\title{
Children's toxicology from bench to bed - Liver Injury (4): Mitochondrial respiratory chain disorder and liver disease in children
}

\author{
Kei Murayama ${ }^{1}$ and Akira Ohtake ${ }^{2}$ \\ 'Department of Metabolism, Chiba Children's Hospital, 579-1 Heta-Cho, Midori-Ku, Chiba 266-0007, Japan \\ 2Department of Pediatrics, School of Medicine, Saitama Medical University, 38 Morohongo, Moroyama, Iruma-gun, \\ Saitama 350-0495, Japan
}

(Received February 17, 2009)

\begin{abstract}
Objectives: The present study was aimed to ascertain the contributions of mitochondrial respiratory chain (MRC) enzymes to the development of liver failure and to the liver pathophysiology of metabolic liver diseases. Methods: We investigated liver samples obtained from 8 patients with liver failure due to unknown etiology and from 15 patients with metabolic disease: ornithine transcarbamylase deficiency, 6 cases; Wilson disease, 3 cases; metylmalonic aciduria (MMA); 3 cases, neonatal hemochromatosis, 2 cases. The estimation of MRC enzymes was carried out by the following independent methods; i) blue native polyacrylamide gel electrophoresis (BN-PAGE) in gel enzyme staining, ii) BN-PAGE western blotting, iii) in vitro MRC enzyme assay. Furthermore, we estimated the quantities of mtDNA and nDNA using qPCR. Result: 4 cases with liver failure showed low activities and protein levels of complex I, III and IV. We also performed qPCR and estimated the ratio mtDNA/nDNA using these samples. They all exhibited extremely low ratio. They were diagnosed as mtDNA depletion syndrome. All cases except MMA cases exhibited mildly or moderately suppressed activities of complex I-IV. However, the respective protein levels remained almost normal. MMA cases exhibited low activities and protein levels of complex I, III and IV. In particular, their low activities and protein levels of complex I were noticeable. They all exhibited normal ratios of mtDNA to nDNA. Conclusion: MRC defect might be an etiology of liver failure in a considerable number of patients in Japan. The present study suggested that considerable disturbance of MRC occurs in children with metabolic diseases and possibly modifies the pathophysiology.
\end{abstract}

Key words: Mitochondrial respiratory chain disorder, Mitochondrial DNA depletion syndrome, Metabolic liver disease, Metylmalonic aciduria

\section{INTRODUCTION}

Congenital disorders of the mitochondrial respiratory chain enzymes are the most common group of inborn errors of metabolism, affecting at least 1 in 5,000 individuals (Skladal et al., 2003; Thorburn, 2004; Munnich and Rustin, 2001). It can affect most organ systems, alone or in combination, so it is not surprising that these disorders could be associated with liver disease presenting as liver failure.

A considerable number of patients with liver failure remain undiagnosed in Japan. They often show liver steatosis, suggesting the presence of mitochondrial damage. On the other hand, mitochondrial damage secondary to metabolic disease, which should modify the liver patho- physiology, has never been investigated sufficiently.

We present here mitochondrial respiratory disorder and liver disease, especially mitochondrial DNA depletion syndrome and secondary effect to metabolic liver disease.

\section{MATERIALS AND METHODS}

\section{Subject}

We investigated the mitochondrial respiratory chain enzymes in liver samples obtained from 8 patients with liver failure due to unknown etiology (Table 1) and from 15 patients with metabolic disease: ornithine transcarbamylase deficiency 6 cases; Wilson disease 3 cases; methylmalonic aciduria (MMA) 3 cases, neonatal hemochromatosis 2 cases (Table 2). 
Table 1. Case profiles with liver failure unknown etiology

\begin{tabular}{|c|c|c|c|c|}
\hline & Case 1 & Case 2 & Case 3 & Case 4 \\
\hline Onset age & Day 8 & Day 2 & 8 months & 4 months \\
\hline Family history & Elder brother $(+)$ & Elder sister $(+)$ & Elder brother $(+)$ & Younger sister $(+)$ \\
\hline Symptoms & $\begin{array}{l}\text { Low birth weight } \\
\text { Feeding difficulty } \\
\text { Nystagmus } \\
\text { MR }\end{array}$ & $\begin{array}{c}\text { Tachypnea, } \\
\text { Hypoglycemia } \\
\text { MR }\end{array}$ & $\begin{array}{l}\text { Failure to thrive } \\
\text { MR } \\
\text { Intractable diarrhea }\end{array}$ & $\begin{array}{c}\text { Failure to thrive } \\
\text { Feeding difficulty } \\
\text { Hypotonia } \\
\text { Deafness }\end{array}$ \\
\hline \multicolumn{5}{|l|}{ Liver function } \\
\hline GOT / GPT (IU/l) & $120 / 46$ & $49 / 215$ & $109 / 42$ & $390 / 218$ \\
\hline T-Bil / D-Bil (mg/dl) & $2.5 / 1.7$ & $9.6 / 1.4$ & $0.7 /-$ & $1.6 /-$ \\
\hline $\mathrm{ChE}(\mathrm{U} / \mathrm{l})$ & 179 & - & - & 73 \\
\hline PT (\%) & 16 & 2-4 (INR) & 63 & 35 \\
\hline Lactate / pyrvate (mmol/1) & $2.9 / 0.13$ & $20.9 / 0.27$ & $1.46 / 0.07$ & $1.76 / 0.1$ \\
\hline Others & AFP $3.4 \times 10^{5} \mathrm{ng} / \mathrm{ml}$ & & & \\
\hline Pathology & \multicolumn{4}{|c|}{ Micro / Macrovesicular steatosis, Fibrosis (mild - moderate) in portal area (P-P bridging) } \\
\hline Transplantation & 8 months & Not performed & Scheduled & Not performed \\
\hline Status & Alive & Dead & Alive & Dead \\
\hline
\end{tabular}

\begin{tabular}{lcccc}
\hline & Case 5 & Case 6 & Case 7 & Case 8 \\
\cline { 2 - 5 } Onset age & 5 months & 2 months & 4 months & 1 months \\
\hline Family history & Not paticular & Not paticular & Not paticular & Not paticular \\
\hline Symptoms & Failure to thrive & Failure to thrive & Heart Failure (EFE) & Failure to thrive \\
& Feeding difficulty & Hypoglycemia & Hypotonia & Jaundice \\
& & Hypotonia & & \\
& & & & \\
\hline
\end{tabular}

\section{Liver function}

GOT / GPT (IU/1)

T-Bil / D-Bil (mg/dl)

$\mathrm{ChE}(\mathrm{U} / \mathrm{l})$

PT (\%)

Lactate / pyrvate $(\mathrm{mmol} / \mathrm{l})$

Others

Pathology

Transplantation

Status

$489 / 176$
$5.7 / 4.3$
105
60

$3.2 / 0.1$

\section{$209 / 92$}

$3.7 / 2.2$

198

33.2

$1.6 / 0.1$ unknown

$328 / 129$

$35.4 / 25.6$

150

22

unknown

$63.3 /-$ $\mathrm{AFP}>5.0 \times 10^{4} \mathrm{ng} / \mathrm{ml}$

\begin{tabular}{cccc}
$\begin{array}{l}\text { Macrovesicular } \\
\text { steatosis }\end{array}$ & $\begin{array}{l}\text { Nodular cirrhosis } \\
\text { Extensive fibrosis }\end{array}$ & $\begin{array}{l}\text { Macrovesicular } \\
\text { steatosis }\end{array}$ & Extensive fibrosis \\
\hline Scheduled $\rightarrow$ Stopped & 9 months & Not performed & Not performed \\
\hline Dead & Alive & Dead & Dead \\
\hline
\end{tabular}

\section{Determinations of enzyme activities}

Activities of respiratory chain complexes I, II, III and IV were assayed for the crude post- $600 \mathrm{~g}$ supernatant of the liver samples as described previously (Rahman et al., 1996; Murayama et al., 2008). Each complex activity was presented as a percent ratio relative to the mean value obtained from 35 healthy controls. Together, for each patient, the percent ratios of complex I, II, III and IV 
activities to the citrate synthase (CS) as a mitochondrial enzyme marker or complex II activity were calculated.

\section{BN-PAGE western blotting}

Expressions of the mitochondrial respiratory chain complex I, II, III and IV proteins in the liver were examined by western blotting using blue native polyacrylamide gel electrophoresis (BN-PAGE) according to the methods described previously (Dabbeni-Sala et al., 2001; Schägger et al., 1988). Ten $\mu \mathrm{g}$ weight of the protein in mitochondria-enriched fraction was separated by BNPAGE. Immunostaining was performed using a monoclonal antibody specific for the $39 \mathrm{kD}$ subunit of complex I, $70 \mathrm{kD}$ subunit of complex II, core 1 subunit of complex III and subunit 1 of complex IV (Molecular Probes, Eugene, OR, USA).

\section{Quantitative PCR}

The quantitative estimation of mtDNA was performed by the real-time amplification of fragments of nicotinamide adenine dinucleotide dehydrogenase 1 (ND1) in mtDNA genome, as previously described (Pagnamenta et al., 2006; He et al., 2002). To determine the overall abundance of mtDNA, we compared the real-time amplification of ND1 with single-copy nuclear reference gene (exon 24 of the cystic fibrosis transmembrane conductance regulator (CFTR) gene; chosen on account of the lack of single-nucleotide polymorphisms). For both experiments, DNA from six adult liver samples (from needle biopsies, obtained with informed consent) was used as controls, and results are the means of four independent runs, with samples assayed in triplicate in each run.

\section{RESULTS AND DISCUSSION}

8 cases with liver failure showed extremely low activities and protein levels of complex I, III and IV (Figs. 1 and 2). We also performed qPCR and estimated the

Table 2. The cases with metabolic liver disease which were investigated respiratory chain enzymes

\begin{tabular}{c}
6 cases of OTC Deficiency \\
Male 3 cases \\
Female 3 cases \\
\hline 4 cases of Wilson Disease \\
Wilsonian fluminant 3 cases \\
Liver cirrhosis $\quad 1$ case \\
\hline 2 cases of Neonatal Hemochromatosis \\
\hline 3 cases of Methylmalonic Aciduria \\
\hline
\end{tabular}

Table 3. Respiratory chain enzyme analysis

i) In vitro respiratory chain enzyme assay

ii) BN-PAGE in gel enzyme staining

iii) BN-PAGE western blotting

iv) Quantitative PCR

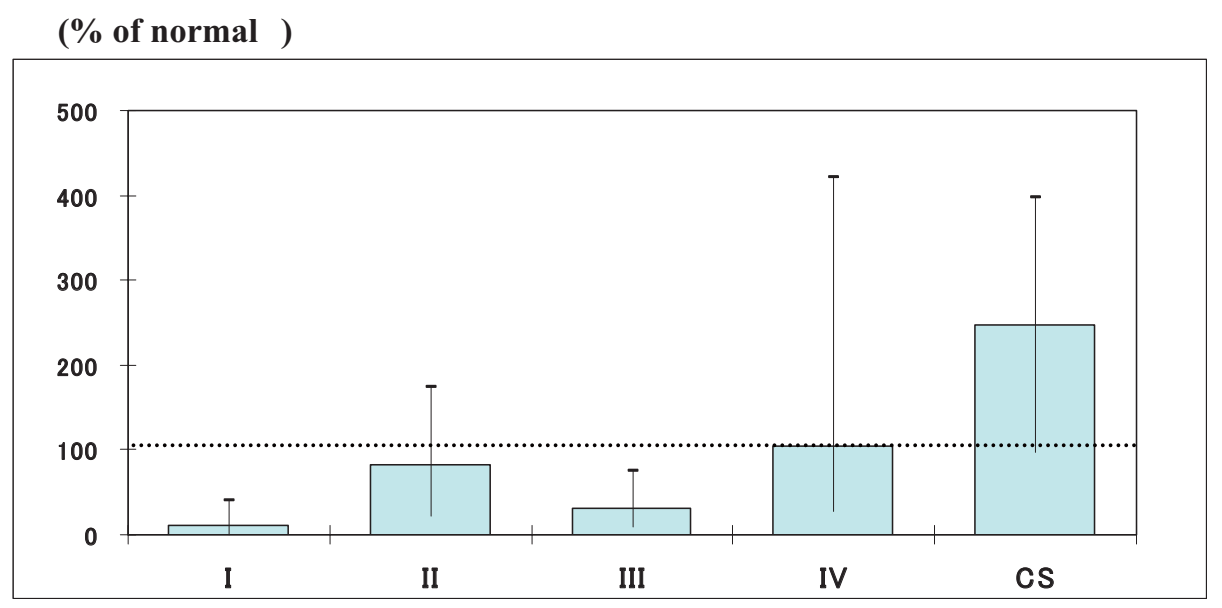

I; Complex I II; Complex II III; Complex III IV; Complex IV CS; Citrate synthase

Fig. 1. The results of enzyme assay of respiratory chain in eight cases. Complex I and III were extremely low activities. 
ratio mtDNA/nDNA using these samples (Fig. 3). They all exhibited extremely low ratio (2-7\%; normal is 60 $150 \%$ ). Based on these data, they were diagnosed as mtDNA depletion syndrome. Thus, the present study showed that primary mitochondrial hepatopathies were mainly caused by mtDNA depletion.

In the metabolic liver diseases, all cases except MMA cases exhibited mildly or moderately suppressed activities of complex I, II and IV (also complex II in some cases). However, the respective protein levels remained almost normal in them (Figs. 4 and 5).

Unlike other metabolic diseases, MMA cases exhibited low activities and protein levels of complex I, III and IV as did patients with mtDNA depletion syndrome. In particular, their low activity and protein levels of complex
I was noticeable. Surprisingly, they all exhibited normal ratios of mtDNA to nDNA (Fig. 6 and Table 4). However, the mechanism underlying depleted $\mathrm{RC}$ proteins in an absence of depletion of mtDNA remains unclear.

The mitochondrial respiratory chain transfers electrons derived from oxidation of sugars, fats and proteins through a series of four enzyme complexes to generate an electrochemical proton gradient. ATP synthase, or complex V, then utilizes this gradient to derive ATP synthesis. This process of oxidative phosphorylation is responsible for bulk of ATP synthesis in virtually all tissue, so it is not surprising that $\mathrm{RC}$ dysfunction can affect any or all organ systems including liver (Thorburn, 2004; Munnich and Rustin, 2001).

Lactic academia is the classic biochemical finding of

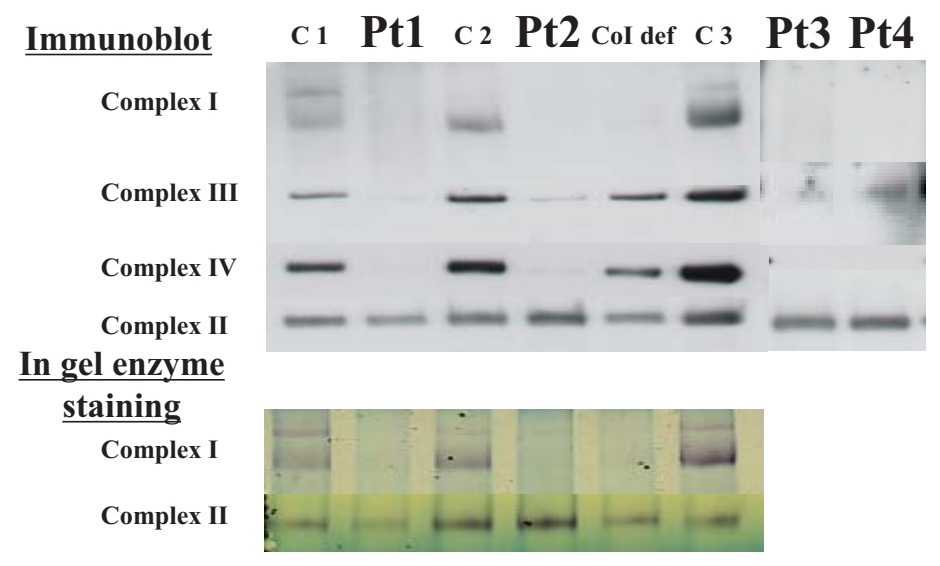

Fig. 2. BN-PAGE and Western blotting in case1-4. The bands of complex I, III, and IV were significantly decreased.

The percentage of mtDNA/nDNA was caluculated by the real-time PCR. ND1 probe of mtDNA Exon 24 of the CFTR probe of nuclear DNA (He et al., 2002)

mtDNA/nDNA ( $\%$ of control)

\begin{tabular}{ccccccccc}
\hline Case & 1 & 2 & 3 & 4 & 5 & 6 & 7 & 8 \\
\hline$(\%)$ & 2.3 & 2.8 & 6.6 & 3.3 & 11.5 & 23.7 & 4.6 & 18.4 \\
\hline
\end{tabular}

Normal range: $60-150 \%$

\section{Diagnosis: Mitochondrial DNA Depletion Syndrome}

Fig. 3. The ratio of mtDNA/nDNA by the real-time PCR. All cases are significantly low ratio of mtDNA (normal range; 40-150\%). 
Mitochondrial function in liver disease

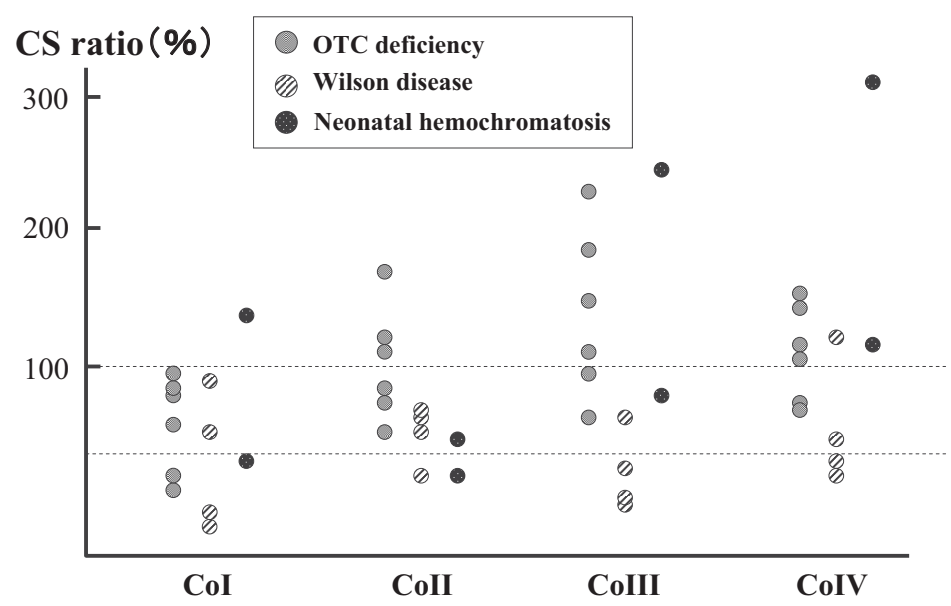

Fig. 4. The result of enzyme assay of respiratory chain in 12 cases with metabolic liver disease (OTC deficiency, Wilson disease, and Neonatal hemochromatosis).

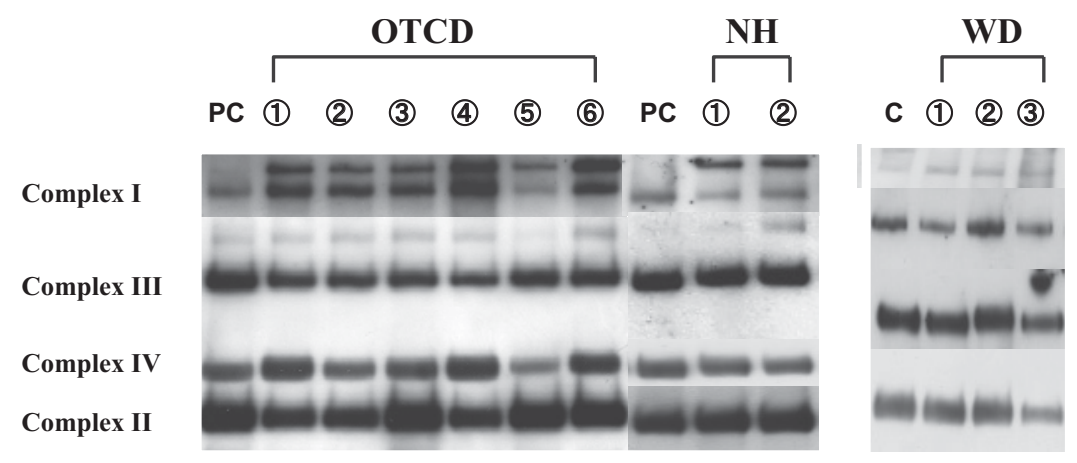

OTCD; OTC deficiency, NH; Neonatal hemochromatosis, WD; Wilson disease

Fig. 5. BN-PAGE and Western blotting in the cases with metabolic liver disease (OTC deficiency, Wilson disease, and Neonatal hemochromatosis).

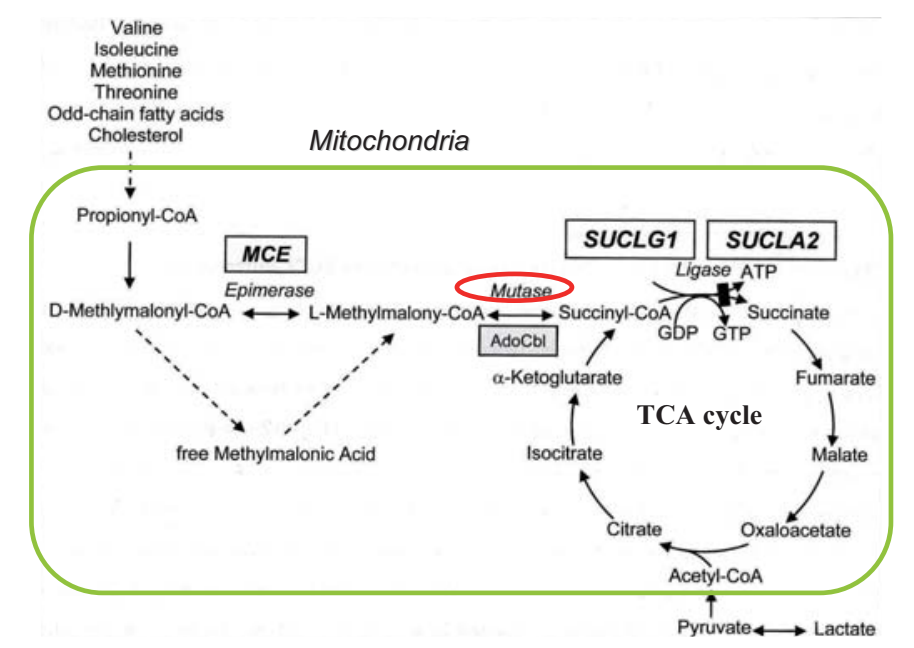

Fig. 6. Metabolic pathway about methylmalonic aciduria. 


\section{Enzyme activity}

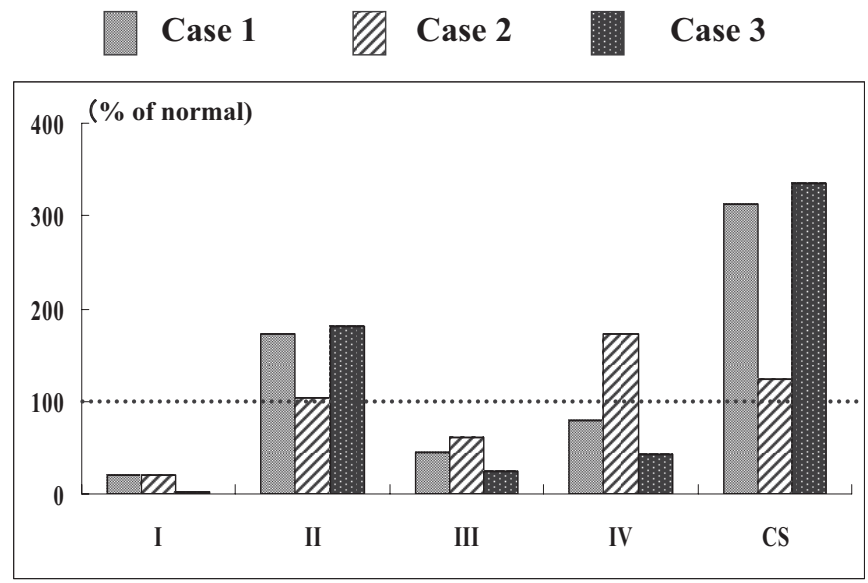

\section{Western blotting}

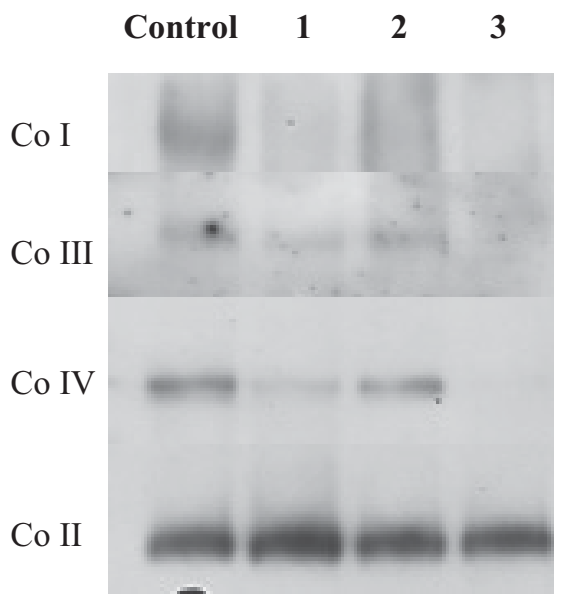

Fig. 7. The result of enzyme activity and BN-PAGE analysis of respiratory chain in methylmalonic aciduria.

Table 4. The ratio of $\mathrm{mtDNA} / \mathrm{nDNA}$ by the real-time PCR in methylmalonic aciduria

\begin{tabular}{ccc}
\hline \multicolumn{3}{c}{ mtDNA/nDNA (\% of control) } \\
\hline Case 1 (F) & Case 2 (M) & Case 3 (F) \\
49 & 48 & 113 \\
\hline
\end{tabular}

Normal range: $40-150 \%$

mitochondrial disease, but Kirby et al. (1999) reported that blood lactic acid level was normal in about 20 percent of patients with complex I deficiency. About a half of our patient usually showed normal blood lactate level.

Recently, BN-PAGE immunoblotting and enzyme staining have been shown to be a powerful diagnostic tool for mitochondrial disorders. We confirmed their utility in studying these patients. More investigation is required to acquire a better understanding of liver disease mitochondrial respiratory chain disorders.

The present study strongly suggested that considerable disturbance of mitochondrial respiratory chain occurs in children with metabolic diseases and possibly modifies the pathophysiology of the liver disease.

\section{ACKNOWLEDGMENT}

This peer-reviewed article is based upon a lecture presented at the 35th Annual Meeting of Japanese Society of Toxicology, June 2008 in Tokyo under the theme of
“Children's Toxicology”, June 2008 in Tokyo.

\section{REFERENCES}

Dabbeni-Sala, F., Di Santo, S., Franceschini, D., Skaper, S.D. and Giusti, P. (2001): Melatonin protects against 6-OHDA-induced neurotoxicity in rats: a role for mitochondrial complex I activity. FASEB J., 15, 164-170.

He, L., Chinnery, P.F., Durham, S.E., Blakely, E.L., Wardell, T.M., Borthwick, G.M., Taylor, R.W. and Turnbull, D.M. (2002): Detection and quantification of mitochondrial DNA deletions in individual cells by real-time PCR. Nucleic Acids Res., 30, e68.

Kirby, D.M., Crawford, M., Cleary, M.A., Dahl, H.H., Dennett, X. and Thorburn, D.R. (1999): Respiratory chain complex I deficiency: an underdiagnosed energy generation disorder. Neurology, 52, 1255-1264.

Munnich, A. and Rustin, P. (2001): Clinical spectrum and diagnosis of mitochondrial disorders. Am. J. Med. Genet., 106, 4-17.

Murayama, K., Nagasaka, H., Tsuruoka, T., Omata, Y., Horie, H., Tregoning, S., Thorburn, D.R., Takayanagi, M. and Ohtake, A. (2008): Intractable secretory diarrhea in a Japanese boy with mitochondrial respiratory chain complex I deficiency. Eur. J. Pediatr. [Epub ahead of print]

Pagnamenta, A.T., Taanman, J.W., Wilson, C.J., Anderson, N.E., Marotta, R., Duncan, A.J., Bitner-Glindzicz, M., Taylor, R.W., Laskowski, A., Thorburn, D.R. and Rahman, S. (2006): Dominant inheritance of premature ovarian failure associated with mutant mitochondrial DNA polymerase gamma. Hum. Reprod., 21, 2467-2473.

Rahman, S., Blok, R.B., Dahl, H.H., Danks, D.M., Kirby, D.M., Chow, C.W., Christodoulou, J. and Thorburn, D.R. (1996): Leigh syndrome: clinical features and biochemical and DNA abnormalities. Ann. Neurol., 39, 343-351.

Schägger, H., Aquila, H. and Von Jagow, G. (1988): Coomassie 


\section{Mitochondrial function in liver disease}

blue-sodium dodecyl sulfate-polyacrylamide gel electrophoresis for direct visualization of polypeptides during electrophoresis. Anal. Biochem., 173, 201-205.

Skladal, D., Halliday, J. and Thorburn, D.R. (2003): Minimum birth prevalence of mitochondrial respiratory chain disorders in children. Brain, 126, 1905-1912.

Thorburn, D.R. (2004): Diverse powerhouses. Nat. Genet., 36, 1314. 
